\title{
Advances in T-cell checkpoint immunotherapy for head and neck squamous cell carcinoma
}

This article was published in the following Dove Press journal:

OncoTargets and Therapy

\author{
Xinmeng $\mathrm{Qi}^{1,2, *}$ \\ Bo Jia ${ }^{3, *}$ \\ Xue Zhao' \\ Dan Yu'
}

'Department of Otolaryngology

Head and Neck Surgery, The Second

Hospital, Jilin University, Changchun,

Jilin, ${ }^{2}$ Department of Otolaryngology

Head and Neck Surgery, Beijing

Tongren Hospital, Capital Medical

University, ${ }^{3}$ Department of Thoracic

Medical Oncology, Peking University

Cancer Hospital and Institute, Beijing

People's Republic of China

*These authors contributed equally to this work
Correspondence: Dan Yu

Department of Otolaryngology Head and Neck Surgery, The Second Hospital, Jilin University, 218 ZiQiang Street, Changchun, Jilin I3004I, People's

Republic of China

Tel +86 I3 756003630

Email yudan19792003@I63.com

\begin{abstract}
Head and neck squamous cell carcinoma (HNSCC) has been found to be a complex group of malignancies characterized by their profound immunosuppression and high aggressiveness. In most cases of advanced HNSCC, treatment fails to obtain total cancer cure. Efforts are needed to develop new therapeutic approaches to improve HNSCC outcomes. In this light, T-cells "immune checkpoint" has attracted much attention in cancer immunotherapy. It has been broadly accepted that inhibitory T-cell immune checkpoints contribute to tumor immune escape through negative immune regulatory signals (cytotoxic T-lymphocyte-associated antigen 4 [CTLA-4], programmed cell death 1 [PD-1], B7-H3, and B7-H4, etc). Current data suggest that PD-1 and CTLA-4 receptors can inhibit T-cell receptors and T-cell proliferation. Blockade of PD-1/PD-L1 and/or CTLA-4/CD28 pathways has shown promising tumor outcomes in clinical trials for advanced solid tumors like melanoma, renal cell cancer, and non-small cell lung cancer. The present review attempts to explore what is known about PD-1/PD-L1 and CTLA-4/CD28 pathways with a focus on HNSCC. We further discuss how these pathways can be manipulated with therapeutic intent.
\end{abstract}

Keywords: immune checkpoint, PD-1/PD-L1, CTLA-4, HNSCC, immunotherapy

\section{Introduction}

It has been projected that 450,000 new cases of head and neck squamous cell carcinoma (HNSCC) are diagnosed worldwide each year, which is the sixth most common cancer among human malignancies. ${ }^{1}$ Of these diagnoses, $\sim 90 \%-95 \%$ fall into the histological subtype of HNSCC, ${ }^{2}$ including nasopharyngeal carcinoma (NPC), oropharyngeal carcinoma, laryngeal carcinoma, and hypopharyngeal carcinoma. Unlike many other epithelial malignancies, the majority of HNSCC present at a locally advanced stage with $5 \%-10 \%$ cervical lymph node metastases. If diagnosed at an early stage, HNSCC could be treated with traditional surgery, also radiation plus chemotherapy. For recurrent or metastatic (R/M) HNSCC conditions, cytotoxic chemotherapy remains the standard therapeutic option. Recommended first-line chemotherapy regimens include cisplatin or carboplatin plus 5-Fu, cisplatin or carboplatin plus docetaxel or paclitaxel, etc. Adding cetuximab, an epidermal growth factor receptor (EGFR) monoclonal antibody (mAb), could improve survival compared with palliative chemotherapy alone, but resulting in a median survival of only 10.1 months. A number of recent studies have focused on immunotherapy which is considered to be an alternative treatment approach for cancers in general, while several studies are underway testing the effectiveness of immunotherapeutic strategies in HNSCC which is commonly understood as an immunosuppressive disease. Despite approaches targeting growth factors and receptors such as epidermal growth factor receptor (EGFR), cell surface associated or polymorphic epithelial 
mucin (MUC-1), the receptor for advanced glycation end products (RAGE), G antigen (GAGE) families, melanomaassociated antigens A (MAGE-A) and various cytokines and tumor antigens ${ }^{3-5}$ interfering with known molecular pathways activated in HNSCC have been extensively studied; only few and limited benefit has been seen to be sufficient to prevent tumor progression. Since around 2010, inhibitory checkpoint molecules have been considered as new targets for cancer immunotherapies due to the effectiveness of two checkpoint inhibitor drugs that were initially indicated for advanced melanoma - Keytruda (pembrolizumab), targeting programmed cell death 1 (PD-1) receptor, ${ }^{6}$ and Yervoy (ipilimumab), targeting cytotoxic T-lymphocyte-associated antigen 4 (CTLA-4), ${ }^{7}$ which called attention to the possibility of T-cell checkpoint immunotherapy for HNSCC. In this review, we will summarize the latest developments of T-cell checkpoint immunotherapy in HNSCC, with a particular focus on PD-1 and CTLA-4.

\section{T-cell recognition and immune checkpoints \\ T-cell activation}

It is now established that various components in the immune system play pivotal roles in protecting humans from cancer. It has been broadly recognized that T-cell-dependent immune response specific to tumor antigens plays a crucial role in tumor immune surveillance and that the critical effector cells of adaptive antitumor immunity are the activated $\mathrm{CD} 8^{+}$ cytotoxic T-lymphocytes (CTLs). ${ }^{8}$ T-cells have been the primary focus of cancer immunotherapy primarily due to their ability to initiate diverse immunoreactions via $\mathrm{CD} 4^{+}$helper T-cells that provoke innate and adaptive immunity. ${ }^{9}$ To evoke their proper activation, two sets of signals are required from antigen presenting cells (APCs) regulating T-cell survival, proliferation, and immune response in the lymph node. In a normally functioning immune system, the first signal initiates through binding of T-cell receptor (TCR) and a matching antigen packaged onto major histocompatibility complex (MHC) proteins on APCs. However, this interaction is not sufficient for complete T-cell activation and tumor cytolysis. A second co-stimulatory signal is needed to promote T-cell clonal expansion and cytokine secretion. The best understood co-stimulatory signal pathways are engagements of CD28 on T-cells with CD80 or CD86 (B7 superfamily genes) on APCs. In order to ensure that $\mathrm{T}$-cell activation can only be stimulated by appropriate antigens and maintain their immunologic homeostasis, T-cell-mediated immunity is simultaneously controlled by co-inhibitory signals which are transduced by immune inhibitory checkpoints expressed upon T-cells such as CTLA-4 and PD-1. ${ }^{10}$ Under physiologic conditions, a balance between co-stimulatory and co-inhibitory signals is crucial to determine whether T-cells are activated or become anergic to the specific antigens displayed on the MHC molecules. These immune checkpoints are responsible for immune homeostasis and the maintenance of organ-specific tolerance in normal tissue, protecting organs from unnecessary damage while immune system could still eliminate pathogens efficiently. ${ }^{11}$ Therefore, immune checkpoint molecules highly expressed in the tumor microenvironment are one of the main reasons for tumor immune escape and therapy failure. In this case, the balance between co-signals is greatly biased toward the side of inhibitory factors, resulting in T-cell functions dampened and antitumor responses significantly restricted.

\section{Immune checkpoints}

Tumors develop numerous strategies to avoid detection and eradication by the host immune system. An enhanced understanding of the precise activators and inhibitors of the immune system has brought about therapeutic advances in cancer treatment. Currently, there are several "targetable" immune checkpoint blockade molecules. Lymphocyte activation gene 3 works to suppress the immune response via regulatory $\mathrm{T}$-cells (Tregs) and direct effects on $\mathrm{CD}^{+}$ T-cells. T-cell immunoglobulin domain and mucin domain-3 triggers cell death to negatively regulate Th1/Tc1 functions upon binding its ligand galectin-9. Among all the inhibitory checkpoint molecules, two that have been shown to be clinically effective are PD-1 and CTLA-4.

\section{PD-I and PD-LI/2}

PD-1 (CD279) is a 288 amino acid type I transmembrane protein encoded by the $P D C D 1$ gene on chromosome 2 in humans. It presents not only on effector T-cells, but also on activated myeloid lineage cells such as monocytes, dendritic cells (DCs), and natural killer (NK) cells, suggesting its contribution to other important immune cell functions. ${ }^{12,13}$ PD-1 comprises an extracellular $\mathrm{IgV}$ region, a transmembrane domain, and an intracellular tail containing an immune tyrosine-based inhibitory motif followed by an immune receptor inhibitory tyrosine-based switch motif. ${ }^{12}$ PD-1 receptor has two ligands, PD-L1 and PD-L2. ${ }^{14}$ PD-L1 (B7-H1/ CD274) is a type I transmembrane protein of the CD28 family encoded by the CD274 gene on homo chromosome 9. It is found constitutively on APCs, non-hematopoietic cells, and nonlymphoid organs. ${ }^{12}$ PD-L2 (B7-DC/CD273) is expressed only upon professional APCs, which is in line with its 
function of regulating T-cell priming. Compared to PD-L2, PD-L1, with a broader expression profile, is involved in delivering negative signals of T-cell activation and regulating cytokine expression and secretion. Through binding with the two ligands of PD-1 receptor, PD-1 delivers an inhibitory signal to shut down T-cell function. Many studies recently showed that the expression of PD-L1 is closely related to tumor grade in several types of malignancies and has become a new diagnostic and prognostic biomarker for tumors. ${ }^{10}$ PD-L1, highly expressed on tumor cells, ${ }^{15-21}$ binds with TCR PD-1, negatively regulates T-cell response, resulting in tumor antigen-specific T-cells-induced apoptosis and anergy, and makes the cancer cells evade immune surveillance and killing.

PD-1/PD-L1 signaling pathway is involved in the process of immune regulation through several distinct mechanisms. The ligation of PD-L1/PD-L2 to PD-1 inhibits the PI3K/AKT pathway and downregulates expression of the antiapoptotic gene Bcl-xl to promote T-cell apoptosis. ${ }^{22}$ The binding of PD-1 and PD-L1 restricts naive T-cell migration and accumulation in APCs and downregulates TCR, which prevents effective antigen presentation. ${ }^{23}$ PD-1-PD-L1/2 ligation upregulates expression of gene PTEN causing blockade of Akt/mTOR/S6 pathway, and converts $\mathrm{Th} 1^{+} \mathrm{CD} 4^{+} \mathrm{T}$-cells to become Foxp $3^{+}$Tregs that restrain cell-mediated immunity, which is in line with exhaustion of tumor infiltrated lymphocytes (TILs) in the tumor microenvironment. ${ }^{24}$

\section{CTLA-4}

CTLA-4 or CD152 was first discovered to belong to the immunoglobulin super family when researchers were screening the cDNA library. ${ }^{25}$ A later study showed that CTLA-4 knockout mice suffered from massive lymphoproliferation and severe autoimmune disease resulting in tissue destruction and death within 3-4 weeks of age, which demonstrated that the CTLA-4 receptor is an important negative co-stimulatory signal for T-cell activation and proliferation. ${ }^{26,27}$ Currently, it is well established that CTLA-4 is a CD28 homologue with $>30 \%$ of similar sequence expressed exclusively on the surface of T-cells upon activation, but with a much higher binding affinity for CD80 (B7.1) and CD86 (B7.2) than CD 28 (about 10-40 fold). ${ }^{28}$

The engagement of CTLA-4 and CD80/86 competes with that of CD28 causing direct inhibition of antigen presenting followed by T-cell anergy. ${ }^{29-31}$ Besides "stealing" B7 from CD28, other mechanisms of CTLA-4 as an inhibitory signal for immune response have also been proposed. Some studies suggest that engagement of CTLA-4 with B7 itself may transduce inhibitory signals that antagonize the stimulatory signals from CD28 and TCR. ${ }^{32-34}$ CTLA-4 may increase T-cell mobility resulting in decreased effective antigen presentation. ${ }^{35}$ In vitro and in vivo studies have shown that deficiency of CTLA-4 in Tregs leads to systemic lymphoproliferation, fatal T-cell-mediated autoimmune disease, increased IgE production, and furthermore, potent tumor immunity. Constitutive expression of CTLA- 4 by CD4 ${ }^{+}$Tregs is critical for their immune-suppressive function. ${ }^{36,37}$

\section{Correlation of immune inhibitors expression in HNSCC with tumor prognosis}

Of late, many studies have shown that the expression of immune checkpoint is demonstrably correlated with tumor grade or prognosis in several types of malignancies and has become a new biological index for tumor detection and prognosis. ${ }^{38}$ The expression of CTLA-4 and PD-1 in Tregs of HNSCC tumor tissue is higher than that in peripheral blood, which confirms that Tregs in tumor tissues have more immune suppression features. ${ }^{39}$ Montler et al investigated the expression of CTLA-4 and PD-1 on effector T-cells from peripheral blood and tumor tissue in 29 HNSCC patients after surgery, and the data suggested that the two proteins were increased significantly in all T-cell subsets isolated from tumor compared with peripheral blood lymphocytes (PBLs) from the same patient. ${ }^{40}$ And, the level of PD- 1 is even higher on effector $\mathrm{CD} 4^{+}$and $\mathrm{CD} 8^{+} \mathrm{T}$-lymphocytes of human papilloma virus (HPV)-positive HNSCC patients. Malm et al showed that the PD-1 expression in healthy peripheral blood donors is generally under $15 \%$, while the rate surged to over $50 \%$ of both the $\mathrm{CD}^{+}$and $\mathrm{CD} 8^{+} \mathrm{T}$-cells among the PBLs, draining lymph nodes and TILs in the tumor microenvironment in HNSCC patients. ${ }^{41}$ The ligand of PD-1, PD-L1, has been shown in different solid tumors including HNSCC and studies have found that PD-L1 was present in $66 \%-87 \%$ of HNSCC primary tumors. ${ }^{42}$ Chikamatsu et al demonstrated that the expression of PD-L1 on myeloid-derived suppressor cells in the peripheral blood of HNSCC patients was higher than that in the healthy control group. ${ }^{43}$

\section{Oropharynx squamous cell carcinoma (OPSCC) and PD-I/PD-LI}

Besides the usual risk factors of tobacco and alcohol addiction, an increasing proportion of OPSCC is related to the most common high-risk HPV genotype, HPV-16, accounting for $5 \%-20 \%$ of the total HNSCC cases worldwide. ${ }^{44}$ Given the recognized significance of HPV as an emerging etiological 
risk factor for OPSCC, several investigators recently managed to correlate the expression of PD-L1 with HPV status. In the study of Lyford-Pike et al, 59\% of the 20 analyzed HPV-HNSCC samples displayed PD-L1. PD-L1 expression was present in 70\% HPV mRNA-positive cases versus $29 \%$ in those that were HPV-negative. ${ }^{45}$ In a study of 181 OPSCC patients, Ukpo et al found that $46.4 \%$ of the samples were positive of PD-L1 expression with rates of $49.2 \%$ and $34.1 \%$ in the HPV (+) and HPV (-) groups, respectively. The majority of $\mathrm{CD}^{+}$TILs in HPV (+) OPSCC samples produce the cytokine interferon- $\gamma$, which upregulates PD-L1 expression on the surface of tumor cells. Twenty eight cases of recurrence and distant metastases showed PD-L1 expression of $43 \%$ and $70 \% .{ }^{46}$ Furthermore, with the novel tissue microarray technique, an even higher rate of PD-L1 expression could be identified.

\section{Oral cavity squamous cell carcinoma (OSCC) and PD-I/PD-LI}

Both patients with OSCC and actinic cheilitis (AC), an oral premalignant lesion, presented much higher percentage of PD-1 expression in peripheral blood and lesions than normal individuals. And there is an increased proportion of PD-1 in tumor cells from OSCC patients than lesion cells from patients with AC. In all, $21.1 \% \pm 14.6 \%$ of the lymphocytes were $\mathrm{CD}^{+} \mathrm{PD}-1^{+} \mathrm{T}$-cells in OSCC, but AC samples showed only $0.84 \% \pm 0.6 \% \mathrm{CD} 8^{+} \mathrm{PD}-1^{+} \mathrm{T}$-cells among their lymphocytes. The number of CD4 $4^{+} \mathrm{PD}-1^{+}$cells was also higher in OSCC than in the AC group. ${ }^{47}$ A study conducted by Zhang et al investigated PBLs of 82 OSCC patients and 25 healthy individuals using flow cytometry analysis. Their data showed a significant difference in the percentage of PD-1 and PD-L1 expression on $\mathrm{CD}^{+}$and $\mathrm{CD}^{+}$T-cells in PBLs of OSCC patients $\left(\mathrm{CD} 4^{+} \mathrm{PD}-1^{+} 11.4 \% \pm 1.3 \%, \mathrm{CD}^{+} \mathrm{PD}-1^{+} 10.6 \% \pm 1.8 \%\right.$; CD4 $\left.{ }^{+} \mathrm{PD}-\mathrm{L}^{+}+9.5 \% \pm 1.6 \%, \mathrm{CD} 8+\mathrm{PD}-\mathrm{L}^{+}{ }^{+} 20.8 \% \pm 2.8 \%\right)$ and the control subjects (CD4 $4^{+} \mathrm{PD}-1^{+} 5.5 \% \pm 0.9 \%, \mathrm{CD}^{+} \mathrm{PD}-1^{+}$ $6.7 \% \pm 1.2 \%$; CD $4{ }^{+} \mathrm{PD}-\mathrm{L} 1^{+} 5.0 \% \pm 1.1 \%, \mathrm{CD} 8^{+} \mathrm{PD}-\mathrm{L} 1^{+}$ $9.2 \% \pm 1.6 \%$ ). Moreover, the soluble PD-1 level in plasma was also higher in OSCC group than in normal controls. ${ }^{48}$

\section{NPC and PD-I/PD-LI}

Analysis of 59 nasopharyngeal tumor specimens presented high levels of PD-1 (67.8\%, 40/59) and PD-L1 mRNA $(66.6 \%, 20 / 30)$, whereas there was no PD-L1 detected in healthy nasopharyngeal tissues. These results suggested that expression of PD-L1 was not significantly correlated with age and gender, but had strong correlations with clinical tumor stage, lymphatic metastasis, and local recurrence. ${ }^{49}$
The expression rate of $\mathrm{PD}-1$ and $\mathrm{PD}-\mathrm{L} 1$ has been investigated in $\mathrm{CD}^{+}$and $\mathrm{CD}^{+}$T-cells in 28 NPC patient samples. Twenty-eight point four percent and $3.9 \%$ of $\mathrm{CD}^{+} \mathrm{T}$-cells were found to be PD-1-positive in nasopharyngeal tumor tissues and controls, respectively. As for PD-L1, all the 28 NPC tissues were positive for PD-L1, while 79\% $(23 / 29)$ of the nasopharyngeal control subjects were found to be PD-L1 ${ }^{+}$. Eighteen out of 28 cases of NPC expressed B7-H1 on $\mathrm{EpCAM}^{+}$epithelial cells. ${ }^{50}$

\section{Laryngeal carcinoma and PD-I/PD-LI}

To study the expression of PD-L1 in human laryngeal carcinoma tissues and peritumoral tissues, Cao et al assessed the expression of PD-L1 in 31 cases of laryngeal carcinoma and 24 cases of paraneoplastic tissues, and demonstrated that PD-L1 was significantly higher in poorly and moderately differentiated larynx squamous carcinoma than that in well-differentiated tumor tissues. Immunohistochemical analysis showed that PD-L1 was mainly expressed in blood vessels and rarely in cancer cells in poorly and moderately differentiated groups, but displayed weakly positive in blood vessels and partially positive in cancer cells of the welldifferentiated group. PD-L1 expression was intensely correlated with lymphatic metastasis. The expression of PD-L1 in the surrounding tissues was significantly lower than that in cancer tissues, but the rates were in keeping with that of tumor tissues. ${ }^{51}$ Automated quantitative protein analysis was utilized to examine PD-L1 protein expression on TILs in 260 laryngeal squamous cell cancer patients. Scientists speculated that superior disease-free survival and overall survival (OS) were both correlated with PD-L1 levels. And, mRNA level of PD-L1 was up-modulated in tumors compared to paraneoplastic tissues. ${ }^{52}$

\section{Esophageal squamous cell carcinoma (ESCC) and PD-I/PD-LI}

The expression of PD-1 was detected by immunohistochemical Streptavidin-perosiase (SP) analysis in 118 cases of ESCC (54.2\%), 39 cases of adjacent atypical hyperplasia (35.9\%), and 39 cases of normal esophageal tissues $(2.6 \%) .{ }^{53}$ Results of another research found that 26 of the 54 (48.15\%) esophageal carcinoma tissues were positive for B7-H1 protein expression, while normal esophageal tissues were totally negative for both B7-H1 mRNA and protein expression. Scientists further explored the relationship between B7-H1 expression and prognostic clinical parameters. They found no association between B7-H1 expression and age, gender, tumor size, location, or differentiation. In contrast, 
the expression of B7-H1 was significantly correlated to invasion depth, lymphatic metastasis, distant metastasis, and pT classification of the tumor. ${ }^{54}$

\section{HNSCC and CTLA-4 (role of CTLA-4 in HNSCC)}

Jie et al isolated TILs and lymphocytes from peripheral blood from a group of HNSCC patients and discovered that CTLA-4 was displayed more frequently on intratumoral Tregs than circulating Tregs. ${ }^{55} \mathrm{~A}$ study conducted among laryngeal squamous cell carcinoma patients demonstrated that intracellular CTLA-4 presented with a higher expression in $\mathrm{CD} 8^{+}$lymphocytes among patients than in control subjects $(8.2 \% \pm 8.7 \%$ vs $2.3 \% \pm 3.5 \%)$. These rates in $\mathrm{CD} 4+$ and $\mathrm{CD} 19^{+}$lymphocytes were also significantly higher in patients. In terms of surface CTLA- 4 , the difference was only detected in the case of $\mathrm{CD} 8^{+}$lymphocytes $(0.7 \% \pm 0.6 \%$ vs $0.3 \% \pm 0.3 \%) .{ }^{56}$ NPC patients with lower tumor CTLA-4 expression were found to have higher 3-year OS rates (91.4\%), failure-free survival rates $(82.8 \%)$, and distant failure-free survival rates $(85.8 \%)$ than those who fell into the high CTLA-4 expression group $(81.2 \%, 68.0 \%$, and $72.3 \%$, respectively). ${ }^{57}$ Expression of CTLA- 4 was present in $87 \%(137 / 158)$ of the ESCC cases. With respect to tumor imaging metrics core, 65 patients (42.2\%) fell into the negative category, while $89(57.8 \%)$ patients were found positive for CTLA-4 expression. Scientists further speculated that the OS of CTLA-4 ESCC patients (65 months) was longer than that of the CTLA- $4^{+}$group (36 months).$^{58}$

Several studies have explored the association between oncogenesis and CTLA-4 single nucleotide polymorphisms (SNPs), namely +49A/G (rs231775), $-1661 \mathrm{~A} / \mathrm{G}$ (rs4553808), -318C/T (rs5742909), -1722T/C (rs733618), and CT60G/A (rs3087243) SNPs, etc. ${ }^{59,60}$ Kämmerer et al found that the genotype CTLA-4 $(-1661 \mathrm{~A} / \mathrm{G})$ was detected more frequently in patients with OSCC than in healthy controls, and that several combinations of SNPs were found only in patient tissues. ${ }^{61}$ However, a study conducted by Wong et al demonstrated that there was no significant difference in CTLA-4 SNPs between OSCC and control groups. They found that the genotype CTLA-4 A/A was correlated with a younger onset age and lower survival rate. ${ }^{62} \mathrm{~A}$ hospital-based case-control study and meta-analysis results suggest that in the Chinese Han population, the CTLA- $4+49$ G $>$ A polymorphism was not associated with the risk of developing esophageal cancer. ${ }^{63}$ Another case-control study among the Chinese population showed that there was significant association in the frequency of CTLA-4 $+49 \mathrm{~A} / \mathrm{G}$ and NPC risk. ${ }^{64}$ Therefore, the correlation between CTLA-4 SNPs and their roles in cancerogenesis in HNSCC remains to be further studied.

\section{Checkpoint inhibitors as novel strategies for HNSCC and clinical outcome}

Immunotherapies against existing tumors include diverse approaches, ranging from stimulating effector mechanisms to eliminating inhibitory mechanisms. ${ }^{38}$ In conventional cancer immunotherapy, the aim is focused on "putting the weights on the stimulatory side". However, unfortunately, it is difficult to provide sufficient stimulatory co-signals to exceed heavily inhibitory factors in the tumor microenvironment. Even though such methods could be performed on patients in clinical practice, their adverse effects associated with over-activation of immune cells in non-tumoral organs would be extremely severe. ${ }^{65}$ As mentioned above, immune checkpoint molecules, which belong to inhibitory co-signals, exist to counteract stimulatory co-signals. Currently, several mAbs targeting those molecules have been developed to "decrease the weights from the inhibitory side" and have shown impressive promise in Phase I-III clinical trials for advanced solid tumors like melanoma, renal cell cancer, and non-small cell lung cancer. ${ }^{66-68}$ Unlike conventional antibodies used for the treatment of tumors, antibodies that block immune checkpoints do not bind directly to the tumor cells, but target lymphocyte receptors or their ligands to modulate their antitumor activity. Among these immune checkpoint blockades, ipilimumab (anti-CTLA-4 antibody), nivolumab, and pembrolizumab (anti-PD-1 antibody) have been designed and used in some solid tumors to block coinhibitory signaling, recovering the CTL from anergy in the antitumor immune response. ${ }^{69,70}$ It has been reported that, compared to traditional modalities, those Abs display superior clinical efficacies with long-term disease remission and increased objective response rates in selected patients. The anti-CTLA-4 mAb ipilimumab was first approved as a new agent by the US Food and Drug Administration (FDA) for the treatment of high-risk and metastatic postoperative melanoma. In addition to anti-CTLA-4, mAbs targeting PD-1 and its ligand PD-L1 have also been investigated as important therapeutic tools in several early phase clinical trials. Based on intriguing preclinical data from many groups, several ongoing clinical trials (Table 1) are investigating the role of immune checkpoint blockades in R/M HNSCC including single agent and combinations with tumor vaccines, chemotherapy, or radiation. ${ }^{71}$ Each of these categories will be discussed briefly below. 
Table I Ongoing clinical trials evaluating immune checkpoint inhibitors in HNSCC

\begin{tabular}{|c|c|c|c|c|c|}
\hline Trial identifier & Drug & Phase & $\begin{array}{l}\text { Immune } \\
\text { checkpoint } \\
\text { target }\end{array}$ & Disease/tumor type & $\begin{array}{l}\text { Primary } \\
\text { outcome } \\
\text { measures }\end{array}$ \\
\hline NCT0I848834 & $\begin{array}{l}\text { Pembrolizumab } \\
\text { (MK-3475) }\end{array}$ & IB & PD-I & R/M HNSCC & $\begin{array}{l}\text { OR } \\
\text { ORR } \\
\text { OS } \\
\text { PFS }\end{array}$ \\
\hline NCT02I05636 & Nivolumab & III & PD-I & R/M HNSCC & $\begin{array}{l}\text { ORR } \\
\text { OS }\end{array}$ \\
\hline NCT0235803। & $\begin{array}{l}\text { Pembrolizumab } \\
\text { (MK-3475) }\end{array}$ & III & PD-I & R/M HNSCC & PFS \\
\hline NCT02296684 & $\begin{array}{l}\text { Pembrolizumab } \\
\text { (MK-3475) }\end{array}$ & II & PD-I & $\begin{array}{l}\text { Locoregionally advanced surgically } \\
\text { resectable HNSCC }\end{array}$ & $\begin{array}{l}\text { Locoregional } \\
\text { recurrence rates; } \\
\text { distant failure rate }\end{array}$ \\
\hline NCT02252042 & Pembrolizumab & III & PD-I & R/M HNSCC & PFS, OS \\
\hline NCT02255097 & Pembrolizumab & II & PD-I & R/M HNSCC & ORR \\
\hline NCT02289209 & Pembrolizumab + RT & II & PD-I & $\begin{array}{l}\text { Locoregional inoperable recurrence } \\
\text { or } 2 \text { nd primary HNSCC }\end{array}$ & PFS \\
\hline NCT0233558 & Nivolumab & II & PD-I & $\mathrm{R} / \mathrm{M}$ nasopharyngeal cancer & $\begin{array}{l}\text { Objective tumor } \\
\text { response per } \\
\text { RECIST criteria }\end{array}$ \\
\hline NCT0I693562 & $\begin{array}{l}\text { Durvalumab } \\
\text { (MEDI-4736) }\end{array}$ & $\mathrm{I} / \mathrm{II}$ & PD-LI & $\begin{array}{l}\text { Solid tumors } \\
\text { (including HNSCC) refractory to } \\
\text { standard therapy }\end{array}$ & OR \\
\hline NCT02499328 & $\begin{array}{l}\text { Durvalumab } \\
(\text { MEDI-4736) }+ \\
\text { either AZD9150 or } \\
\text { AZD5069 }\end{array}$ & $1 / I I$ & PD-LI & R/M HNSCC & $\begin{array}{l}\text { Safety/efficacy } \\
\text { ORR }\end{array}$ \\
\hline NCT0229I055 & $\begin{array}{l}\text { Durvalumab } \\
(\text { MEDI-4736) }+ \\
\text { ADXSII-00I }\end{array}$ & $\mathrm{I} / \mathrm{II}$ & PD-LI & $\begin{array}{l}\text { Previously treated locally advanced } \\
\text { or metastatic cervical or } \mathrm{HPV}^{+} \\
\text {HNSCC }\end{array}$ & Safety/efficacy \\
\hline NCT0I860430 & $\begin{array}{l}\text { Ipilimumab-concurrent } \\
\text { cetuximab and IMRT }\end{array}$ & IB & CTLA-4 & $\begin{array}{l}\text { AJCC stage III/IVB } \\
\text { HNSCC, excluding TINI }\end{array}$ & Ipilimumab dose \\
\hline NCT0I93592I & $\begin{array}{l}\text { Ipilimumab-concurrent } \\
\text { cetuximab and IMRT }\end{array}$ & I & CTLA-4 & R/M HNSCC & $\begin{array}{l}\text { PFS } \\
\text { Ipilimumab dose }\end{array}$ \\
\hline \multicolumn{6}{|c|}{ Combinatorial immunotherapy } \\
\hline NCT0255III59 & $\begin{array}{l}\text { Durvalumab } \\
(\text { MEDI-4736) }+ \\
\text { tremelimumab }\end{array}$ & III & $\begin{array}{l}\text { PD-LI and } \\
\text { CTLA-4 }\end{array}$ & R/M HNSCC & PFS, OS \\
\hline NCT02369874 & $\begin{array}{l}\text { Durvalumab } \\
(\text { MEDI-4736) }+ \\
\text { tremelimumab }\end{array}$ & III & $\begin{array}{l}\text { PD-LI and } \\
\text { CTLA-4 }\end{array}$ & R/M HNSCC & OS, PFS \\
\hline NCT023I 9044 & $\begin{array}{l}\text { Durvalumab } \\
(\text { MEDI-4736) }+1- \\
\text { tremelimumab }\end{array}$ & II & $\begin{array}{l}\text { PD-LI and } \\
\text { CTLA-4 }\end{array}$ & R/M HNSCC & ORR \\
\hline NCT0226274I & $\begin{array}{l}\text { Durvalumab } \\
(\text { MEDI-4736) }+ \\
\text { tremelimumab }\end{array}$ & I & $\begin{array}{l}\text { PD-LI and } \\
\text { CTLA-4 }\end{array}$ & R/M HNSCC & Safety \\
\hline
\end{tabular}

Abbreviations: PFS, progression-free survival; ORR, overall response rate; OS, overall survival; RT, radiation therapy; IMRT, intensity-modulated radiotherapy; HNSCC, head and neck squamous cell carcinoma; PD-I, programmed cell death I; CTLA-4, cytotoxic T-lymphocyte-associated antigen 4; R/M, recurrent or metastatic; HPV, human papilloma virus; AJCC, American Joint Committee on Cancer; OR, odds ratio; RECIST, response evaluation criteria in solid tumors.

\section{Anti-CTLA-4}

The anti-CTLA-4 antibody ipilimumab has shown the greatest clinical curative effect in patients with advanced melanoma in two randomized Phase III trials. ${ }^{72}$ Some observations have recently evaluated the role of CTLA-4 as a potential therapeutic target in HNSCC. In a cohort of patients with HNSCC $(n=22)$, treatment with cetuximab increased the expression of CTLA-4 in the majority of intratumoral Tregs, and it was also demonstrated that ipilimumab can decrease suppression of NK cells from Tregs. ${ }^{73}$ Ipilimumab is currently being assessed in clinical trials in combination with cetuximab and intensity-modulated radiotherapy in patients with 
advanced HNSCC (NCT01860430 and NCT01935921). ${ }^{74}$ Tremelimumab (CP-675, 206) is a fully humanized mAb specific for CTLA-4, which has been successfully used to treat patients with metastatic melanoma and some other cancers. Currently, clinical testing of tremelimumab for HNSCC in combination with other therapies including cetuximab and intensity-modulated radiation therapy (IMRT) is underway (NCT01860430).

\section{Anti-PD- I}

Regarding anti-PD-1 antibodies, the humanized pembrolizumab and fully human nivolumab are IgG4 mAbs that block the binding of PD-1 receptor to PD-L1 and PD-L2. Pembrolizumab (also named MK-3475), with a high affinity for PD-1, is the first mAb targeting PD-1 approved by the FDA, which has been the most extensive immunotherapeutic strategy in HNSCC. An ongoing multicenter Phase I trial (KEYNOTE-012, NCT01848834) is the largest to date completed immune checkpoint therapy trial in HNSCC. Preliminary results show that $49.5 \%$ of patients demonstrated partial response or stable disease following treatment with pembrolizumab given a fixed dose of $200 \mathrm{mg}$ every 3 weeks. Eighty six percent of these patients demonstrated durable responses. ${ }^{75}$ In another ongoing clinical trial, of the 104 patients with head and neck cancer who were enrolled, the overall response rate (ORR) was $18.2 \%$; response rates were similar regardless of HPV status. ${ }^{71}$ Pembrolizumab has shown minimal adverse effects when administered in head and neck cancer patients. ${ }^{76}$ Further updates on this trial reported that pembrolizumab was twice as effective as cetuximab in HNSCC, with disease control of 50\% and tumor shrinkage in $57 \%$ of patients. ${ }^{77}$ In a combined update of two cohorts of patients with R/M HNSCC that was heavily pre-managed, pembrolizumab resulted in a response rate of $24 \%$ and an additional $25 \%$ of patients with stable disease, which were both slightly improved compared with earlier reports. ${ }^{78}$ Another trial KEYNOTE-048 evaluating pembrolizumab either as monotherapy or in combination with chemotherapy versus standard chemotherapy is underway in patients with R/M HNSCC (NCT02358031). Pembrolizumab is also currently being assessed in conjunction with re-irradiation and as part of primary treatment in multiple clinical settings (NCT02289209, NCT02296684). Some Phase II/III trials are underway to evaluate the clinical efficacy (ORR, response duration, and side effects) of pembrolizumab in R/M HNSCC (NCT02255097, NCT02252042). Nivolumab, a fully human immunoglobulin G4 PD-1 immune checkpoint inhibitor antibody, was active and generally well tolerated in patients with advanced solid tumors. In patients with HNSCC refractory to platinum therapy, a randomized Phase III trial of nivolumab (NCT02105636) resulted in improved OS compared with treatment with the weekly methotrexate, docetaxel, or cetuximab (NCT02105636). Furthermore, a Phase II nivolumab monotherapy study for R/M NPC is currently in progress (NCT02339558).

\section{Anti-PD-LI}

At present, representative antibodies targeting PD-L1 include BMS-936559 (also known as MDX1105), MPDL3280A, and durvalumab (MEDI-4736), which have been applied as monotherapy or adjuncts to conventional therapies in clinical trials for a variety of tumors. ${ }^{79}$ Two ongoing Phase I trials, with antiPD-L1 mAb (IgG1 isotype) MEDI-4736 (NCT01693562) and anti-PD-1 mAb (IgG4 isotype) MK-3475 (NCT01848834), have recruited cohorts of $\mathrm{R} / \mathrm{M}$ HNSCC patients. The disease control rate at 6 months was 15\% (18\% for PD-L1-positive vs $11 \%$ for PD-L1-negative), and the ORR in patients with HNSCC was $11 \%$. Efficacy of durvalumab, an engineered IgG1 antibody to PD-L1, has also been tested among 62 patients with R/M HNSCC. Results showed an ORR of $12 \%$, and the duration of response ranges from 4 to 43 weeks. A second trial (NCT02291055) has combined PD-L1 inhibitor durvalumab (MEDI-4736) with ADXS11-001, live attenuated Listeria monocytogenes engineered to express, and subsequently elicit, an immune response against an HPV-16-E7 fusion protein. ${ }^{80}$ In another randomized Phase I/II trial to assess the combination of MEDI-4738 with either AZD9150 or AZD5069 in patients with metastatic squamous cell carcinoma of head and neck (NCT02499328), the clinical safety/ efficacy and ORR are being evaluated.

\section{Combinatorial immunotherapy clinical trials in HNSCC}

Some studies are currently active or under development to investigate the efficacy of immune checkpoint inhibitors in combination with one another. Some trials evaluating the utility of MEDI-4736 monotherapy alone or in conjunction with tremelimumab (anti-CTLA-4) compared to the standard treatment for first-line R/M HNSCC are ongoing (NCT02551159, NCT02369874, NCT02319044). This is a novel perspective in the application of immune therapy, and the results as well as analysis of the outcomes are much looked forward to. ${ }^{81,82}$

\section{Conclusion}

HNSCC has been recognized as an immunosuppressive disease. There have been multiple recent developments using immunotherapy for the management of HNSCC patients. Blockades of immune checkpoints have proved to play a 
vital role in enhancing immune surveillance and tumor cell clearance, which provides oncologists with a significant set of antitumor therapies with promising potentials. Studies of immune checkpoint inhibitors should not only lead to a novel strategy for advanced HNSCC, but also for many other solid tumors. However, more investigations are required and further studies need to be better designed to explore the possibility and efficacy of combinations of different agents and still keep an eye on their side effects, thus to bring about more desired tumor outcomes.

\section{Acknowledgments}

This work is supported by the National Natural Science Youth Foundation of China (81502348); the National Natural Science Foundation of China (81572653); and Science and Technology Department of Jilin Province Youth Foundation (20150520042JH).

\section{Disclosure}

The authors report no conflicts of interest in this work.

\section{References}

1. Jemal A, Bray F, Center MM, Ferlay J, Ward E, Forman D. Global cancer statistics. CA Cancer J Clin. 2011;61:69-90.

2. Marur S, Forastiere AA. Head and neck cancer: changing epidemiology, diagnosis, and treatment. Mayo Clin Proc. 2008;83(4):489-501.

3. Götte K, Usener D, Riedel F, Hörmann K, Schadendorf D, Eichmüller S. Tumor-associated antigens as possible targets for immune therapy in head and neck cancer: comparative mRNA expression analysis of RAGE and GAGE genes. Acta Otolaryngol. 2002;122(5):546-552.

4. Young MR, Neville BW, Chi AC, Lathers DM, Boyd Gillespie M, Day TA. Oral premalignant lesions induce immune reactivity to both premalignant oral lesions and head and neck squamous cell carcinoma. Cancer Immunol Immunother. 2007;56(7):1077-1086.

5. Hartmann S, Kipke RU, Rauthe S, et al. Oral brush biopsy and melanomaassociated antigens A (MAGE-A) staining in clinically suspicious lesions. J Craniomaxillofac Surg. 2015;43(10):2214-2218.

6. Merck. FDA approves KEYTRUDA ${ }^{\circledR}$ (pembrolizumab) for the treatment of patients with metastatic non-small cell lung cancer whose tumors express PD-L1 with disease progression on or after platinum-containing chemotherapy. Kenilworth, NJ, USA: Merck; 2015 [October 2]. Available from: http:/www.mrknewsroom.com/ news-release/prescription-medicine-news/fda-approves-keytrudapembrolizumab-treatment-patients-metas. Accessed October 25, 2015.

7. Food and Drug Administration. FDA approves Yervoy to reduce the risk of melanoma returning after surgery [press release]. Silver Spring, MD: US FDA; 2015 [October 28]. Available from: http://www.fda. gov/NewsEvents/Newsroom/PressAnnouncements/ucm469944.htm. Accessed February 29, 2016.

8. Milstein O, Hagin D, Lask A, et al. CTLs respond with activation and granule secretion when serving as targets for T-cell recognition. Blood. 2011;117(3):1042-1052.

9. Joshi RP, Koretzky GA. Diacylglycerol kinases: regulated controllers of T cell activation, function, and development. Int J Mol Sci. 2013; 14(4):6649-6673.

10. Mischinger J, Comperat E, Schwentner C, Stenzl A, Gakis G. Inflammation and cancer: what can we therapeutically expect from checkpoint inhibitors? Curr Urol Rep. 2015;16:59.
11. Jung K, Choi I. Emerging co-signaling networks in T cell immune regulation. Immune Netw. 2013;13(5):184-193.

12. Keir ME, Butte MJ, Freeman GJ, Sharpe AH. PD-1 and its ligands in tolerance and immunity. Annu Rev Immunol. 2008;26:677-704.

13. Francisco LM, Salinas VH, Brown KE, et al. PD-L1 regulates the development, maintenance, and function of induced regulatory $\mathrm{T}$ cells. J Exp Med. 2009;206:3015-3029.

14. He YF, Zhang GM, Wang XH, et al. Blocking programmed death-1 ligand-PD-1 interactions by local gene therapy results in enhancement of antitumor effect of secondary lymphoid tissue chemokine. J Immunol. 2004;173:4919-4928.

15. Thompson RH, Gillett MD, Cheville JC, et al. Costimulatory B7-H1 in renal cell carcinoma patients: indicator of tumor aggressiveness and potential therapeutic target. Proc Natl Acad Sci US A. 2004;101:17174-17179.

16. Boland JM, Kwon ED, Harrington SM, et al. Tumor B7-H1 and B7-H3 expression in squamous cell carcinoma of the lung. Clin Lung Cancer. 2013;14:157-163

17. Velcheti V, Schalper KA, Carvajal DE, et al. Programmed death ligand-1 expression in non-small cell lung cancer. Lab Invest. 2014; 94:107-116.

18. Cooper WA, Tran T, Vilain RE, et al. PD-L1 expression is a favorable prognostic factor in early stage non-small cell carcinoma. Lung Cancer. 2015;89:181-188.

19. Huang Y, Zhang SD, McCrudden C, Chan KW, Lin Y, Kwok HF. The prognostic significance of PD-L1 in bladder cancer. Oncol Rep. 2015;33:3075-3084.

20. Kakavand H, Vilain RE, Wilmott JS, et al. Tumor PD-L1 expression, immune cell correlates and PD-1+ lymphocytes in sentinel lymph node melanoma metastases. Mod Pathol. 2015;28:1535-1544.

21. Nduom EK, Wei J, Yaghi NK, et al. PD-L1 expression and prognostic impact in glioblastoma. Neuro Oncol. 2016;18(2):195-205.

22. Christian JM, Nor Haslinda AA, Jayanta C, et al. Programmed death ligand 1 over-expression correlates with malignancy and contributes to immune regulation in ovarian cancer. Cancer Immunol Immunother. 2014;63(3):215-224.

23. Karwacz K, Bricogne C, MacDonald D, et al. PD-L1 co-stimulation contributes to ligand-induced $\mathrm{T}$ cell receptor down-modulation on CD8+ T cells. EMBO Mol Med. 2011;3:581-592.

24. Amarnath S, Mangus CW, Wang JC, et al. The PDL1-PD1 axis converts human TH1 cells into regulatory T cells. Sci Transl Med. 2011;3:111-120.

25. Brunet JF, Denizot F, Luciani MF, et al. A new member of the immunoglobulin superfamily - CTLA-4. Nature. 1987;328(6127):267-270.

26. Waterhouse P, Penninger JM, Timms E, et al. Lymphoproliferative disorders with early lethality in mice deficient in Ctla-4. Science. 1995; 270(5238):985-988.

27. Tivol EA, Borriello F, Schweitzer AN, Lynch WP, Bluestone JA, Sharpe AH. Loss of CTLA4 leads to massive lymphoproliferation and fatal multiorgan tissue destruction, revealing a critical negative regulatory role of CTLA4. Immunity. 1995;3:541-547.

28. Lenschow DJ, Herold KC, Rhee L, et al. CD28/B7 regulation of Th1 and $\mathrm{Th} 2$ subsets in the development of autoimmune diabetes. Immunity. 1996;5(3):285-293.

29. Linsley PS, Brady W, Urnes M, Grosmaire LS, Damle NK, Ledbetter JA. CTLA-4 is a second receptor for the B cell activation antigen B7. J Exp Med. 1991;174:561-569.

30. Linsley PS, Greene JL, Brady W, Bajorath J, Ledbetter JA, Peach R. Human B7-1 (CD80) and B7-2 (CD86) bind with similar avidities but distinct kinetics to CD28 and CTLA-4 receptors. Immunity. 1994; 1(9):793-801.

31. van der Merwe PA, Bodian DL, Daenke S, Linsley P, Davis SJ. CD80 (B7-1) binds both CD28 and CTLA-4 with a low affinity and very fast kinetics. J Exp Med. 1997;185(3):393-403.

32. Lee KM, Chuang E, Griffin M, et al. Molecular basis of T cell inactivation by CTLA-4. Science. 1998;282(5397):2263-2266.

33. Fallarino F, Fields PE, Gajewski TF. B7-1 engagement of cytotoxic $\mathrm{T}$ lymphocyte antigen 4 inhibits $\mathrm{T}$ cell activation in the absence of CD28. J Exp Med. 1998;188:205-210. 
34. Masteller EL, Chuang E, Mullen AC, Reiner SL, Thompson CB. Structural analysis of CTLA-4 function in vivo. J Immunol. 2000;164: 5319-5327.

35. Schneider H, Downey J, Smith A, et al. Reversal of the TCR stop signal by CTLA-4. Science. 2006;313:1972-1975.

36. Takahashi $\mathrm{T}$, Tagami $\mathrm{T}$, Yamazaki $\mathrm{S}$, et al. Immunologic self-tolerance maintained by $\mathrm{CD} 25(+) \mathrm{CD} 4(+)$ regulatory $\mathrm{T}$ cells constitutively expressing cytotoxic T lymphocyte-associated antigen 4. J Exp Med. 2000;192:303-309.

37. Wing K, Onishi Y, Prieto-Martin P, et al. CTLA-4 control over Foxp3+ regulatory T cell function. Science. 2008;322(5899):271-275.

38. Farkona S, Diamandis EP, Blasutig IM. Cancer immunotherapy: the beginning of the end of cancer? BMC Med. 2016;14(1):73.

39. Zandberg DP, Strome SE. The role of the PD-L1:PD-1 pathway in squamous cell carcinoma of the head and neck. Oral Oncol. 2014;50: 627-632.

40. Montler R, Bell RB, Thalhofer C, et al. OX40, PD-1 and CTLA-4 are selectively expressed on tumor-infiltrating $\mathrm{T}$ cells in head and neck cancer. Clin Transl Immunol. 2016;5(4):e70.

41. Malm IJ, Bruno TC, Fu J, et al. Expression profile and in vitro blockade of programmed death-1 in human papilloma virus-negative head and neck squamous cell carcinoma. Head Neck. 2015;37(8):1088-1095.

42. Cho YA, Yoon HJ, Lee JI, Hong SP, Hong SD. Relationship between the expressions of PD-L1 and tumor-infiltrating lymphocytes in oral squamous cell carcinoma. Oral Oncol. 2011;47:1148-1153.

43. Chikamatsu K, Sakakura K, Toyoda M, Takahashi K, Yamamoto T, Masuyama K. Immunosuppressive activity of CD14+ HLA-DR-cells in squamous cell carcinoma of the head and neck. Cancer Sci. 2012; 103(6):976-983.

44. Zaravinos A. An updated overview of HPV-associated head and neck carcinomas. Oncotarget. 2014;5(12):3956-3969.

45. Lyford-Pike S, Peng S, Young GD, et al. Evidence for a role of the PD-1:PD-L1 pathway in immune resistance of HPV-associated head and neck squamous cell carcinoma. Cancer Res. 2013;73(6):1733-1741.

46. Ukpo OC, Thorstad WL, Lewis JS Jr. B7-H1 expression model for immune evasion in human papilloma virus-related oropharyngeal squamous cell carcinoma. Head Neck Pathol. 2013;7(2):113-121.

47. Malaspina TS, Gasparoto TH, Costa MR, et al. Enhanced programmed death 1 (PD-1) and PD-1 ligand (PD-L1) expression in patients with actinic cheilitis and oral squamous cell carcinoma. Cancer Immunol Immunother. 2011;60:965-974.

48. Zhang P, Ouyang S, Wang J, Huang Z, Wang J, Liao L. [Levels of programmed death-1 and programmed death ligand-1 in the peripheral blood of patients with oral squamous cell carcinoma and its clinical implications]. Hua Xi Kou Qiang Yi Xue Za Zhi. 2015;33(5):529-533. Chinese.

49. Hsu MC, Hsiao JR, Chang KC, et al. Increase of programmed death1-expressing intratumoral CD8 T cells predicts a poor prognosis for nasopharyngeal carcinoma. Mod Pathol. 2010;23:1393-1403.

50. Zhang F, Liu Z, Cui Y, Wang G, Cao P. [The clinical significance of the expression of costimulatory molecule PD-L1 in nasopharyngeal carcinoma]. Lin Chung Er Bi Yan Hou Tou Jing Wai Ke Za Zhi. 2008;22(9):408-410. Chinese

51. Cao P, Cui Y, Liu Z, Zhang F. [Expression and significance of PD-L1 in laryngocarcinoma]. Lin Chung Er Bi Yan Hou Tou Jing Wai Ke Za Zhi. 2008;22(24):1115-1116. Chinese.

52. Maria V, Margaritis A, Vamsidhar V, et al. Evaluation of PD-L1 expression and associated tumor-infiltrating lymphocytes in laryngeal squamous cell carcinoma. Clin Cancer Res. 2016;22(3):704-713.

53. Tan L, Li J, Andom D, et al. Expression of PD-1, CD45RO and OX40 in esophageal squamous cell carcinoma tissue. J Zhengzhou Univ (Med Sci). 2014;49(2):141-145.

54. Meng Q. Expression of B7-H1 in Esophageal Carcinoma and its Impact on T Cell Function. Zhengzhou: Zhengzhou University; 2008:1-2.

55. Jie H-B, Gildener-Leapman N, Li J, et al. Intratumoral regulatory T cells upregulate immunosuppressive molecules in head and neck cancer patients. Br J Cancer. 2013;109(10):2629-2635.
56. Erfani N, Khademi B, Haghshenas MR, Mojtahedi Z, Khademi B, Ghaderi A. Intracellular CTLA4 and regulatory $\mathrm{T}$ cells in patients with laryngeal squamous cell carcinoma. Immunol Invest. 2013; 42(2):81-90.

57. Huang PY, Guo SS, Zhang Y, et al. Tumor CTLA-4 overexpression predicts poor survival in patients with nasopharyngeal carcinoma. Oncotarget. 2016;7(11):13060-13068.

58. Zhang XF, Pan K, Weng DS, et al. Cytotoxic T lymphocyte antigen-4 expression in esophageal carcinoma: implications for prognosis. Oncotarget. 2016;7(18):26670-26679.

59. Sun T, Zhou Y, Yang M, et al. Functional genetic variations in cytotoxic T-lymphocyte antigen 4 and susceptibility to multiple types of cancer. Cancer Res. 2008;68:7025-7034.

60. Ueda H, Howson JM, Esposito L, et al. Association of the T-cell regulatory gene CTLA4 with susceptibility to autoimmune disease. Nature. 2003; 423:506-511.

61. Kämmerer PW, Toyoshima T, Schöder F, et al. Association of T-cell regulatory gene polymorphisms with oral squamous cell carcinoma. Oral Oncol. 2010;46(7):543-548.

62. Wong YK, Chang KW, Cheng CY, Liu CJ. Association of CTLA-4 gene polymorphism with oral squamous cell carcinoma. J Oral Pathol Med. 2006;35(1):51-54.

63. Liu C, Wang Y, Jiang H, et al. Association between cytotoxic T-lymphocyte antigen $4($ CTLA-4) $+49 \mathrm{G}>\mathrm{A}(\mathrm{rs} 231775)$ polymorphism and esophageal cancer: from a case-control study to a meta-analysis. Int J Clin Exp Med. 2015;8(10):17664-17673.

64. Xiao M, Qi F, Chen X, et al. Functional polymorphism of cytotoxic T-lymphocyte antigen 4 and nasopharyngeal carcinoma susceptibility in a Chinese population. Int J Immunogenet. 2010;37(1):27-32.

65. Adachi K, Tamada K. Immune checkpoint blockade opens an avenue of cancer immunotherapy with a potent clinical efficacy. Cancer Sci. 2015;106(8):945-950.

66. Robert C, Schachter J, Long GV, et al. Pembrolizumab versus ipilimumab in advanced melanoma. N Engl J Med. 2015;372(26):2521-2532.

67. Raman R, Vaena D. Immunotherapy in metastatic renal cell carcinoma: a comprehensive review. Biomed Res Int. 2015;2015:367354.

68. Forde PM, Reiss KA, Zeidan AM, Brahmer JR. What lies within: novel strategies in immunotherapy for non-small cell lung cancer. Oncologist. 2013;18(11):1203-1213.

69. Intlekofer AM, Thompson CB. At the bench: preclinical rationale for CTLA-4 and PD-1 blockade as cancer immunotherapy. J Leukoc Biol. 2013;94(1):25-39.

70. Taube JM, Klein A, Brahmer JR, et al. Association of PD-1, PD-1 ligands, and other features of the tumor immune microenvironment with response to anti-PD-1 therapy. Clin Cancer Res. 2014;20(19): 5064-5074.

71. Economopoulou P, Perisanidis C, Giotakis EI, Psyrri A. The emerging role of immunotherapy in head and neck squamous cell carcinoma (HNSCC): anti-tumor immunity and clinical applications. Ann Transl Med. 2016;4(9):173.

72. Page DB, Postow MA, Callahan MK, Wolchok JD. Checkpoint modulation in melanoma: an update on ipilimumab and future directions. Curr Oncol Rep. 2013;15(5):500-508.

73. Jie HB, Schuler PJ, Lee SC, et al. CTLA-4+ regulatory T cells increased in cetuximab-treated head and neck cancer patients suppress NK cell cytotoxicity and correlate with poor prognosis. Cancer Res. 2015;75(11):2200-2210.

74. Aranda F, Vacchelli E, Eggermont A, et al. Trial watch immunostimulatory monoclonal antibodies in cancer therapy. Oncoimmunology. 2014;3:e27297.

75. Seiwert TY, Haddad RI, Gupta S, et al. Antitumor activity and safety of pembrolizumab in patients (pts) with advanced squamous cell carcinoma of the head and neck $(\mathrm{SCCHN})$ : preliminary results from KEYNOTE-012 expansion cohort. J Clin Oncol. 2015;33:LBA6008.

76. Bauml JM, Cohen RB, Aggarwal C. Immunotherapy for head and neck cancer: latest developments and clinical potential. Ther Adv Med Oncol. 2016;8(3):168-175. 
77. Seiwert TY, Burtness B, Mehra R, et al. Safety and clinical activity of pembrolizumab for treatment of recurrent or metastatic squamous cell carcinoma of the head and neck (KEYNOTE-012): an open-label, multicentre, phase 1b trial. Lancet Oncol. 2016;17(7):956-965.

78. Chow LQ, Burtness B, Weiss J, et al. A phase Ib study of pembrolizumab (Pembro; MK-3475) in patients (Pts) with human papilloma virus (HPV)-positive and negative head and neck cancer (HNC). Ann Oncol. 2014;25(5):1-41.

79. Hamanishi J, Mandai M, Matsumura N, Abiko K, Baba T, Konishi I. PD-1/PD-L1 blockade in cancer treatment: perspectives and issues. Int J Clin Oncol. 2016;21:462-473.
80. Chervin CS, Brockstein B. Current clinical immunotherapeutic approaches for head and neck cancer. F1000Res. Epub 2016 May 5.

81. Hang W, Xu ZX, Zhang Q, Lu X, Liu G. [Immune checkpoint inhibitor therapy in advanced head and neck cancer]. Zhonghua Er Bi Yan Hou Tou Jing Wai Ke Za Zhi. 2017;52(1):67-70. Chinese.

82. Argiris A, Harrington KJ, Tahara M, et al. Evidence-based treatment options in recurrent and/or metastatic squamous cell carcinoma of the head and neck. Front Oncol. 2017;7:72.

\section{Publish your work in this journal}

OncoTargets and Therapy is an international, peer-reviewed, open access journal focusing on the pathological basis of all cancers, potential targets for therapy and treatment protocols employed to improve the management of cancer patients. The journal also focuses on the impact of management programs and new therapeutic agents and protocols on

\section{Dovepress}

patient perspectives such as quality of life, adherence and satisfaction. The manuscript management system is completely online and includes a very quick and fair peer-review system, which is all easy to use. Visit http://www.dovepress.com/testimonials.php to read real quotes from published authors. 